\title{
Sexualidade de mulheres vivendo com HIV/AIDS em São Paulo
}

\author{
Sexuality of women living with HIV/AIDS \\ in São Paulo
}

Vera Paiva 1

Maria do Rosário Latorre 2

Neide Gravato 3

Regina Lacerda 3

Enhancing Care Initiative-Brazil 4

1 Núcleo de Estudos para a Prevenção da AIDS Departamento de Psicologia Social, Instituto de Psicologia, Universidade de São Paulo. Av. Prof. Mello Moraes 1721, São Paulo, SP 05508-900, Brasil. 2 Departamento de Epidemiologia, Faculdade de Saúde Pública, Universidade de São Paulo. Av. Dr. Arnaldo 715, São Paulo, SP 01246-904, Brasil. mdrddola@usp.br

3 Programa Municipal DST/ AIDS de Santos, Associação Santista de Pesquisa Prevenção e Educação em DST/AIDS. Rua Paraguaçu 42,

Santos, SP 11040-000, Brasil. ${ }^{4}$ Enhacing Care Initiative Brazil, coordenado por José Ricardo Ayres (Faculdade de Medicina, Universidade de SãoPaulo-jrcayres@usp.br), e inclui Aloisio Segurado (Faculdade de Medicina, Universidade de São Paulo), Ana Aratangy (Programa de DST/AIDS, Secretaria de Estado da Saúde de São Paulo), Cassia Buchala (Faculdade de Saúde Pública, Universidade de São Paulo), Heloisa H. S. Marques (Instituto da Criança, Faculdade de Medicina, Universidade de São Paulo), Ivan França Jr. (Faculdade de Saúde Pública, Universidade de São Paulo), Marinela Della Negra (Instituto Emílio Ribas), Maria Lucia Salomão (Faculdade de Medicina, Universidade Estadual Paulista).

\begin{abstract}
The social and cultural setting which increases female vulnerability to HIV does not disappear when women living with HIVIAIDS discover that they are infected. Following diagnosis, new challenges arise in their emotional lives, an issue which has received little attention in the literature. This study interviewed 1068 women living with HIVIAIDS using a questionnaire consisting of both open and closed questions, aimed at describing aspects of their sexual and reproductive lives and how they perceive counseling at Reference Centers in two cities in the State of São Paulo, where they have access to free antiretroviral therapy. Of the women with stable sexual partners, $63 \%$ used condoms in all their sexual relations, or three times the national average; $43 \%$ of the partners were HIV-negative and $14 \%$ had unknown serological status; $73 \%$ of the women had children and 15\% were considering becoming pregnant. Knowledge on mother-to-child transmission was less than expected, and the interviewees complained of limited space and receptiveness for discussing sexuality, especially with regard to their childbearing wishes. Counseling on sexuality should be a continuing process and requires interdisciplinary training for the professional team working in health care services, with an emphasis on sexual and reproductive rights. Key words Acquired Immunodeficiency Syndrome; Women's Health; Sex Behavior; Sex Counseling
\end{abstract}

Resumo O contexto sócio-cultural que aumenta a vulnerabilidade feminina ao HIV não desaparece quando as mulheres vivendo com HIVIAIDS (MVA) se descobrem infectadas. Diagnosticadas, novos desafios vão aparecer na sua vida afetiva, poucos descritos na literatura. Foram entrevistadas 1.068 MVA com a utilização de um questionário composto de questões abertas e fechadas, visando descrever aspectos da sua vida sexual e reprodutiva e como elas percebem o aconselhamento nessa área, quando são atendidas em Centros de Referência, em duas cidades de São Paulo onde têm acesso gratuito aos medicamentos anti-retrovirais. Das mulheres que têm parceiro sexual estável, 63\% usam camisinha em todas as relações sexuais, o triplo da média nacional; 43\% dos parceiros são HIV negativos, $14 \%$ têm sorologia desconhecida; $73 \%$ têm filhos e $15 \%$ pensam em tê-los. O conhecimento sobre transmissão materno-infantil é menor do que o esperado, e as entrevistadas referem pouco espaço e acolhimento para discutir sexualidade, em especial suas intenções reprodutivas. O aconselhamento sobre sexualidade deve ser um processo contínuo no atendimento e requer o treinamento interdisciplinar dos profissionais atuando em serviços de saúde, com ênfase nos direitos sexuais e reprodutivos.

Palavras-chave Síndrome de Imunodeficiência Adquirida; Saúde da Mulher; Comportamento Sexual; Aconselhamento Sexual 


\section{Introdução}

Durante muitos anos, especialmente nos países onde a epidemia do HIV/AIDS cresceu mais rapidamente entre os homens, como no Brasil, as mulheres portadoras eram muito pouco visíveis. Somente a partir de 1993, quando a África já contava 4 milhões de mulheres com AIDS e uma mulher para cada homem doente (Mann et al., 1992), a revisão da definição de AIDS incluiu a presença de câncer invasivo de colo do útero como um marcador da doença, independente da presença de outras infecções oportunistas, o que demonstra o reconhecimento tardio da singularidade da infecção do HIV entre as mulheres. No Brasil, maior atenção às especificidades do cuidado das mulheres vivendo com HIV/AIDS (MVA), principalmente no que se refere ao treinamento dos profissionais da rede de atendimento, é estimulada quando a Zidovudine injetável para prevenção da transmissão materno-infantil foi disponibilizada pelo Ministério da Saúde. Nesta época a proporção homem/mulher já era de 2:1 (1997), metade delas vivendo em São Paulo (MS, 2001).

Na literatura disponível, poucos estudos dedicam-se à vida sexual e reprodutiva das portadoras e confirmam que os determinantes sócio-culturais da sexualidade, inclusive do sexo não protegido, são os mesmos entre os portadores e os não-portadores (Santos et al., 1998; Tunala et al., 2000). A sexualidade é uma dimensão da vida que sabemos ser profundamente determinada pelo contexto sócio-cultural em que acontece (Parker \& Galvão, 1996). É importante entender o que as vivências dos pacientes têm em comum e o que é específico de cada indivíduo ou de seu momento na vida, mas devemos entender como os serviços de saúde falham em reduzir a vulnerabilidade do grupo das pessoas vivendo com HIV/AIDS ao adoecimento, ou em promover sua qualidade de vida e saúde integral (Giffin \& Lowndes, 1999; Mann et al., 1992). Como garantir cuidados com a saúde sexual e reprodutiva que considerem os direitos, os valores pessoais e as fases da vida de cada paciente? Como ajudá-los a contar para novos parceiros que são portadores do HIV? Como manter permanentemente a motivação para o uso do preservativo, a necessidade de se proteger (e ao parceiro) da reinfecção? Como lidar com os efeitos psicológicos negativos do diagnóstico na vida sexual, como a depressão e o isolamento?

Os dilemas que afetam a sexualidade das MVA relatados em vários estudos mais recentes (Clark et al., 2000; Feldman \& Maposhere, 2000; Leukefeld et al., 2000; Thioye et al., 2000) indicam que as singularidades de cada grupo estudado são um problema para a generalização das sugestões programáticas em qualquer contexto. Indicam também que passam por um processo de adaptação ao diagnóstico, por várias fases e diversas maneiras de lidar com a vida e com sexualidade (Santos et al., 1998; Schiltz \& Sandforth, 2000; Willians et al., 1996). A maneira de lidar com a sexualidade certamente dependerá da qualidade do apoio e aconselhamento que os portadores recebem nesse processo. O momento do diagnóstico e uma abordagem baseada no diálogo e respeito às decisões do paciente são indicados como cruciais (Santos et al., 1998; Tunala et al., 2000; Williams et al., 1996).

O presente artigo discutirá estas questões valendo-se dos resultados da pesquisa intitulada Vulnerabilidade e o Cuidado com as Pessoas Vivendo com HIV-AIDS - Um Estudo sobre a Assistência às Mulheres Vivendo com HIV-AIDS nos Serviços Públicos de Saúde das Cidades de Santos, São Paulo e São José do Rio Preto, que chamaremos a partir de agora de ECI. Focalizaremos a sexualidade e a percepção que as mulheres entrevistadas têm do acolhimento à sua vida sexual e reprodutiva nos centros em que são atendidas.

\section{Material e métodos}

Foram entrevistadas 1.068 mulheres vivendo com HIV/AIDS, com 18 anos ou mais, atendidas em três grandes centros, considerados referência para o HIV/AIDS no Estado de São Paulo: CRT-DST/AIDS-SP (sede do Programa Estadual, com cerca de 4.700 pacientes em atendimento), Casa da AIDS (ambulatório ligado à Universidade de São Paulo, 3.900 pacientes), Centro de Referência em AIDS de Santos (referência municipal, cerca de 2.100 pacientes/ mês). No período de 21 de setembro de 1999 a 29 de fevereiro de 2000, as mulheres foram convidadas a participar, segundo a ordem de chegada aos serviços para consulta com infectologista. Das convidadas, 5,2\% recusaram-se a participar, e não diferem das entrevistadas no que se refere à renda, escolaridade, local da entrevista e faixa etária (dados não exibidos). Aceito o convite, todas assinaram o termo de consentimento livre e esclarecido e foram entrevistadas por profissionais de saúde treinadas especialmente e em espaço reservado. Este estudo foi aprovado pelas Comissões de Ética das instituições participantes.

O questionário usado para a entrevista incluiu questões abertas e fechadas sobre: carac- 
terização sócio-demográfica, a constituição familiar, tipo de parceria atual, vida sexual e reprodutiva, uso de camisinha, métodos anticoncepcionais, testagem para HIV, percepção de risco, uso de drogas, além de investigação sobre os cuidados que vêm recebendo e sua relação com os serviços em que recebem tratamento.

$\mathrm{Na}$ análise das perguntas fechadas, a população de estudo foi caracterizada por meio de estatística descritiva e foi feito teste de associação pelo qui-quadrado de Pearson para avaliar a associação ente as variáveis de estudo (características sócio-demográficas, de estilo de vida e reprodutivas, da infecção e uso de camisinha) com a faixa etária ou com o tempo de diagnóstico. Na comparação entre as médias, foi utilizado o teste de Kruskal-Wallis e, nas comparações múltiplas destas médias, foi realizado o teste Tukey - honestly significant differences (HSD). O teste de Levene foi utilizado para testar a igualdade das variâncias e o teste de Kolmogorov Smirnov para testar a aderência das variáveis quantitativas à distribuição Normal. Em todas as análises utilizou-se $\mathrm{a}=5 \%$.

Foi criado um escore que chamamos de "espaço" para falar de sexualidade, baseado nas respostas à pergunta: "Você tem facilidade de falar de sua vida sexual com: (a) infectologista, (b) ginecologista, (c) psicólogo, (d) assistente social, (e) enfermeiro?" Para cada uma das cinco especialidades, a resposta podia ser: “(0) nunca fui atendido por ..., ou (1) nunca tive facilidade para falar da vida sexual com..., (2) às vezes tenho facilidade... e (3) na maioria das vezes tenho facilidade...". O escore total descreve graus crescentes de "espaço" para falar sobre sexualidade, podendo variar de 0 (não tem acesso a nenhuma destas especialidades profissionais, portanto nenhum "espaço") a 15 (tem acesso a todos estes profissionais e facilidade para falar sobre sua vida sexual com todos eles, maior "espaço" possível).

Para a análise das perguntas abertas, as respostas foram categorizadas por dois avaliadores independentes que têm experiência de trabalho conjunto e incorporadas ao banco de dados. No caso de discordância entre eles, os investigadores resolviam a categorização em conjunto. As falas, citadas no texto entre aspas, são emblemáticas das categorias encontradas, nem sempre das categorias mais representativas, mas assim mesmo significativas para compreendermos a diversidade da experiência das mulheres que compõem o grupo estudado.

\section{Resultados}

A média de idade das entrevistadas foi de 36 anos, variando entre 18 e 67 anos. Metade das entrevistadas declarou renda abaixo de $\mathrm{R} \$ 200,00$, e cerca de $10 \%$ delas indicaram uma renda por pessoa da família menor que $\mathrm{R} \$ 50,00$ por mês. Metade delas morava em casas de até quatro cômodos (por exemplo: um quarto, uma cozinha, um banheiro, uma sala) e cursou até a $8 \underline{a}$ série. Apenas $30 \%$ delas tinham emprego fixo, $12 \%$ tinham empregos temporários (incluindo $0,4 \%$ de trabalhadoras do sexo), $17 \%$ procuravam emprego, $9 \%$ pararam de procurar emprego, $8 \%$ estavam aposentadas. Perguntadas, $49 \%$ se consideraram brancas, $11 \%$ negras, $40 \%$ morenas, mestiças ou pardas. A Tabela 1 apresenta algumas características dessas mulheres. As mulheres mais velhas tendem a ter menos anos de escola, mais filhos vivos, serem viúvas, conhecerem seu diagnóstico por mais tempo, e relataram menor uso de drogas no momento da entrevista e maior consumo de bebidas alcoólicas (embora a quantidade não indique uso abusivo).

Entre as mulheres na faixa entre 18 a 24 anos, é notável o fato de $20 \%$ não saberem como se infectaram. A maioria das entrevistadas declara que foi infectada pelo parceiro fixo (772 mulheres, entre as quais 240 por parceiros que usavam drogas injetáveis), $7 \%$ em relações sexuais com múltiplos parceiros, $4 \%$ porque compartilharam seringas, $3 \%$ porque receberam sangue contaminado. Quando perguntamos se esperavam receber um resultado positivo do teste HIV, quase dois terços das entrevistadas declararam que jamais pensaram que poderiam estar infectadas no momento de receber o diagnóstico. Apenas 23\% das participantes tomaram a iniciativa de fazer o teste, imaginando que poderiam ter se infectado. A maioria das mulheres foi diagnosticada só quando adoeceu ou por causa da doença do parceiro. Um número significativo fez o teste porque o filho foi diagnosticado (3\%), durante o pré-natal $(9 \%)$ ou na maternidade $(1 \%)$.

\section{Atividade sexual}

O número de parceiros sexuais que tiveram na vida foi em média de 4,5 parceiros, excluindose $18 \%$ delas que responderam "muitos, não sei quantos”. A primeira relação sexual foi, em média, aos 17,5 anos. As mais jovens, além de iniciarem a vida sexual mais cedo, são as que estão há menos tempo com seu parceiro ou menos freqüentemente tinham parceiro fixo, como se observa na Tabela 2. Uma fração relevante de mulheres (27\%) declarou ter sido vítima 
Tabela 1

Número e porcentagem de mulheres, segundo variáveis de estudo e faixa etária.

\begin{tabular}{|c|c|c|c|c|c|c|c|c|c|c|c|c|}
\hline \multirow[t]{3}{*}{ Variável } & \multicolumn{10}{|c|}{ Faixa etária (anos) } & \multirow{3}{*}{$\begin{array}{c}\text { Total } \\
n\end{array}$} & \multirow[t]{3}{*}{$\mathbf{p}^{\#}$} \\
\hline & \multicolumn{2}{|c|}{$18-24$} & \multicolumn{2}{|c|}{$25-29$} & \multicolumn{2}{|c|}{$30-34$} & \multicolumn{2}{|c|}{$35-39$} & \multicolumn{2}{|c|}{$40 e+$} & & \\
\hline & $\mathrm{n}$ & (\%) & $\mathrm{n}$ & $(\%)$ & $n$ & (\%) & $\mathrm{n}$ & (\%) & $\mathrm{n}$ & (\%) & & \\
\hline \multicolumn{13}{|l|}{ Anos de escola* } \\
\hline $0-3$ & 8 & 10 & 17 & 9 & 24 & 11 & 18 & 7 & 69 & 21 & 136 & $<0,001$ \\
\hline $4-7$ & 26 & 33 & 67 & 36 & 65 & 28 & 70 & 30 & 115 & 35 & 343 & \\
\hline $8-11$ & 41 & 51 & 87 & 46 & 111 & 48 & 116 & 49 & 108 & 33 & 463 & \\
\hline $12-13$ & 5 & 6 & 17 & 9 & 29 & 13 & 32 & 14 & 33 & 10 & 116 & \\
\hline \multicolumn{13}{|c|}{ Número de filhos vivos* } \\
\hline 0 & 28 & 35 & 58 & 31 & 60 & 26 & 38 & 16 & 49 & 15 & 233 & $<0,001$ \\
\hline 1 & 30 & 38 & 56 & 30 & 60 & 26 & 51 & 21 & 51 & 16 & 248 & \\
\hline 2 & 15 & 19 & 42 & 22 & 65 & 29 & 78 & 33 & 89 & 27 & 289 & \\
\hline 3 & 6 & 8 & 22 & 12 & 33 & 14 & 41 & 17 & 61 & 19 & 163 & \\
\hline $4 e+$ & - & - & 9 & 5 & 11 & 5 & 30 & 13 & 75 & 23 & 125 & \\
\hline \multicolumn{13}{|l|}{ Estado civil } \\
\hline Unida & 43 & 54 & 87 & 46 & 115 & 50 & 102 & 43 & 105 & 32 & 452 & $<0,001$ \\
\hline Solteira/separada & 34 & 42 & 79 & 42 & 79 & 35 & 84 & 35 & 122 & 38 & 398 & \\
\hline Viúva & 3 & 4 & 22 & 12 & 35 & 15 & 52 & 22 & 98 & 30 & 210 & \\
\hline \multicolumn{13}{|l|}{$\begin{array}{l}\text { Tempo que sabe } \\
\text { diagnóstico (em anos) }\end{array}$} \\
\hline$<1$ ano & 18 & 22 & 28 & 15 & 18 & 8 & 29 & 12 & 28 & 9 & 121 & $<0,001$ \\
\hline $1-4$ anos & 49 & 61 & 102 & 55 & 117 & 51 & 93 & 39 & 160 & 49 & 521 & \\
\hline $5-9$ anos & 11 & 14 & 47 & 25 & 76 & 33 & 93 & 39 & 104 & 32 & 331 & \\
\hline 10 anos e + & 2 & 3 & 10 & 5 & 18 & 8 & 23 & 10 & 32 & 10 & 85 & \\
\hline \multicolumn{13}{|l|}{ Uso de drogas } \\
\hline Usa atualmente & 10 & 13 & 12 & 7 & 26 & 11 & 21 & 9 & 14 & 4 & 83 & $<0,001$ \\
\hline Ex-usuária & 17 & 21 & 44 & 23 & 53 & 23 & 52 & 22 & 34 & 11 & 200 & \\
\hline Nunca usou & 53 & 66 & 132 & 70 & 150 & 66 & 165 & 69 & 277 & 85 & 777 & \\
\hline \multicolumn{13}{|l|}{ Álcool } \\
\hline Sim & 25 & 31 & 60 & 32 & 86 & 38 & 78 & 33 & 83 & 25 & 332 & 0,050 \\
\hline Não & 55 & 69 & 128 & 68 & 143 & 62 & 160 & 67 & 242 & 75 & 728 & \\
\hline \multicolumn{13}{|l|}{ Como se infectou? } \\
\hline Sangue & 1 & 1 & 7 & 4 & 2 & 1 & 11 & 5 & 16 & 5 & 37 & 0,008 \\
\hline Uso de drogas & - & - & 4 & 2 & 9 & 4 & 13 & 5 & 12 & 4 & 38 & \\
\hline Múltiplos parceiros & 7 & 9 & 14 & 7 & 22 & 10 & 19 & 8 & 17 & 5 & 79 & \\
\hline Parceiro fixo & 56 & 70 & 133 & 71 & 172 & 75 & 170 & 71 & 241 & 74 & 772 & \\
\hline Não sabe & 16 & 20 & 26 & 14 & 19 & 8 & 16 & 7 & 35 & 11 & 112 & \\
\hline Vários & - & - & 4 & 2 & 5 & 2 & 9 & 4 & 4 & 1 & 22 & \\
\hline Total & 80 & 100 & 188 & 100 & 229 & 100 & 238 & 100 & 325 & 100 & 1.060 & \\
\hline
\end{tabular}

* excluídas as mulheres com informação ignorada.

$\mathrm{p}^{\#}=$ nível descritivo do teste de associação pelo qui-quadrado. 
Idade na primeira relação sexual e tempo com parceiro fixo segundo idade da mulher.

\begin{tabular}{|c|c|c|c|c|c|c|}
\hline \multirow[t]{2}{*}{ Variável } & \multicolumn{5}{|c|}{ Faixa etária } & \multirow[t]{2}{*}{$p^{*}$} \\
\hline & $18-24$ & $25-29$ & $30-34$ & $35-39$ & 40 e + & \\
\hline \multicolumn{7}{|c|}{ Idade na 1ạ relação sexual } \\
\hline média & 15,8 & 16,4 & 17,4 & 17,7 & 18,3 & $<0,001$ \\
\hline Desvio-padrão & 2,0 & 2,5 & 3,1 & 3,5 & 4,1 & \\
\hline Mínimo-máximo & $12-21$ & $8-26$ & $11-29$ & $6-33$ & $8-34$ & \\
\hline \multicolumn{7}{|c|}{ Tempo com parceiro fixo (em anos) } \\
\hline média & 3,4 & 4,3 & 6,3 & 7,8 & 11,0 & $<0,001$ \\
\hline Desvio-padrão & 2,5 & 3,1 & 4,5 & 6,2 & 10,6 & \\
\hline Mínimo-máximo & $0,2-9,0$ & $0,1-13,0$ & $0,1-18,0$ & $0,1-25,0$ & $0,1-46,0$ & \\
\hline
\end{tabular}

$\mathrm{P}^{\star}=$ nível descritivo do teste Kruskal-Wallis.

de algum tipo de violência sexual em algum momento da vida.

A maioria das entrevistadas (54\%) tinha parceiro e atividade sexual no momento da entrevista (7 mulheres indicaram uma parceira sexual do sexo feminino). O tempo médio dessa relação afetiva era de 6,8 anos (variação de alguns meses a 46 anos), e $91 \%$ comunicaram aos parceiros que são portadoras do HIV. Apenas $2 \%$ das mulheres têm parceiros casuais (não estáveis). O número de casais com sorologia discordante era grande: $24 \%$ das mulheres entrevistadas indicaram um parceiro que é HIV negativo e a mesma proporção de mulheres refere que o parceiro é HIV positivo (24\%). Cerca de $8 \%$ desconhecem o resultado do teste do parceiro, a maioria porque ele se recusou a fazê-lo. As demais não tinham parceiros sexuais no momento da entrevista. Muitas das entrevistadas (20\%) são viúvas porque o marido morreu de AIDS, e, entre elas, $25 \%$ tinham parceiro sexual no momento da entrevista.

A Tabela 3 indica que não foi observada associação entre faixa etária e saber a sorologia do parceiro, o número de parceiros na vida, ou o fato de o parceiro ser soropositivo, e ter ou não acesso ao preservativo. A faixa etária de mais de quarenta anos concentra a mais alta proporção de mulheres que não têm parceiro sexual ou que não moram com o parceiro, ou as que nunca usam o preservativo.

\section{Efeitos do resultado positivo na vida sexual}

Por meio de algumas perguntas abertas, investigamos a qualidade da vida e atividade sexual das participantes, e algumas falas serão incluídas como ilustração.
Perguntamos como descreveriam a vida sexual no momento da entrevista. Entre as mulheres que comentaram a qualidade de sua vida sexual após o diagnóstico $(\mathrm{n}=976)$, algumas lembram que se fortaleceram aceitando o diagnóstico e se preparando para falar dele, ou quando conseguiram incorporar o aconselhamento para as opções de sexo mais seguro. Muitas contaram que passaram por fases, a maioria indicando que a atividade sexual ficou pior logo após o diagnóstico e em seguida se adaptaram. Algumas mulheres indicaram que a vida sexual até melhorou (8\%) depois do diagnóstico, para $24 \%$ delas ficou igual, para $28 \%$ ficou diferente, e para $26 \%$ piorou. Como se vê na Tabela 4 , o tempo de conhecimento do diagnóstico não necessariamente implicou mais facilidade para contá-lo para os parceiros e não afetou o número de parceiros que teve na vida. Aquelas que conheciam seu diagnóstico por menos tempo estavam mais regularmente em uma parceria fixa, tendiam a morar mais freqüentemente com o parceiro, a ter um parceiro soropositivo e a usar mais consistentemente o preservativo. $\mathrm{O}$ acesso ao preservativo não se alterou de modo significativo, segundo o tempo de diagnóstico.

"No inicio do diagnóstico teve aquele impacto, daí ficou diferente, meu marido ficou doente... muito doente! Não tinha como ter relação sexual, depois de mais ou menos dois anos, com a ajuda da psicóloga, voltou a ser normal."

"Não pode ser sem camisinha, mas acostuma e é diferente."

“... quando você fica sabendo você acha que vai morrer amanhã, então...você perde o interesse (sexual)... mas depois você sabe que é igual, que é só usar o preservativo, e tudo bem...daí melhorou." 
Tabela 3

Número e porcentagem de mulheres, segundo variáveis de estudo e faixa etária.

\begin{tabular}{|c|c|c|c|c|c|c|c|c|c|c|c|c|}
\hline \multirow[t]{3}{*}{ Variável } & \multicolumn{10}{|c|}{ Faixa etária (anos)* } & \multirow{3}{*}{$\begin{array}{c}\text { Total } \\
n\end{array}$} & \multirow[t]{3}{*}{$\mathbf{p}^{\#}$} \\
\hline & \multicolumn{2}{|c|}{$18-24$} & \multicolumn{2}{|c|}{$25-29$} & \multicolumn{2}{|c|}{$30-34$} & \multicolumn{2}{|c|}{$35-39$} & \multicolumn{2}{|c|}{$40 e+$} & & \\
\hline & $n$ & $\%$ & $\mathrm{n}$ & $\%$ & $\mathrm{n}$ & $\%$ & $n$ & $\%$ & $\mathrm{n}$ & $\%$ & & \\
\hline \multicolumn{13}{|c|}{$\begin{array}{l}\text { Parceiro sabe que } \\
\text { você é HIV +? }\end{array}$} \\
\hline Sim & 63 & 94 & 112 & 91 & 135 & 91 & 117 & 91 & 105 & 89 & 532 & 0,893 \\
\hline Não & 4 & 6 & 9 & 7 & 8 & 6 & 9 & 7 & 9 & 8 & 39 & \\
\hline Não sabe & - & - & 2 & 2 & 3 & 3 & 2 & 2 & 4 & 3 & 11 & \\
\hline \multicolumn{13}{|c|}{$\begin{array}{l}\text { Número de parceiros } \\
\text { na vida }\end{array}$} \\
\hline $1-2$ & 24 & 35 & 40 & 26 & 57 & 30 & 59 & 31 & 97 & 35 & 277 & 0,155 \\
\hline $3-4$ & 29 & 42 & 60 & 39 & 62 & 33 & 60 & 31 & 101 & 36 & 312 & \\
\hline $5-7$ & 8 & 12 & 35 & 23 & 35 & 19 & 31 & 16 & 57 & 20 & 166 & \\
\hline $8-10$ & 5 & 7 & 12 & 8 & 22 & 12 & 24 & 13 & 17 & 6 & 80 & \\
\hline $11-15$ & 1 & 1 & 4 & 3 & 5 & 3 & 11 & 6 & 6 & 2 & 27 & \\
\hline $16 e+$ & 2 & 3 & 2 & 1 & 5 & 3 & 6 & 3 & 3 & 1 & 18 & \\
\hline \multicolumn{13}{|c|}{ Parceiro fixo? } \\
\hline Sim & 58 & 84 & 100 & 65 & 122 & 66 & 102 & 53 & 99 & 35 & 481 & $<0,001$ \\
\hline Não & 11 & 16 & 53 & 35 & 64 & 34 & 89 & 47 & 182 & 65 & 399 & \\
\hline \multicolumn{13}{|c|}{ Parceiro é HIV +? } \\
\hline Sim & 35 & 52 & 47 & 38 & 61 & 42 & 54 & 42 & 54 & 46 & 251 & 0,317 \\
\hline Não & 22 & 33 & 57 & 47 & 59 & 40 & 58 & 45 & 54 & 46 & 250 & \\
\hline Não sabe & 10 & 15 & 19 & 15 & 26 & 18 & 16 & 13 & 10 & 8 & 81 & \\
\hline \multicolumn{13}{|c|}{ Mora com parceiro? } \\
\hline Sim & 43 & 64 & 85 & 59 & 115 & 70 & 93 & 59 & 84 & 46 & 420 & $<0,001$ \\
\hline Não & 24 & 36 & 58 & 41 & 49 & 30 & 65 & 41 & 100 & 54 & 296 & \\
\hline \multicolumn{13}{|c|}{ Tem usado camisinha } \\
\hline Nunca & 5 & 7 & 14 & 8 & 21 & 11 & 30 & 16 & 43 & 22 & 113 & 0,004 \\
\hline Às vezes & 18 & 25 & 34 & 20 & 42 & 21 & 38 & 20 & 29 & 15 & 161 & \\
\hline Sempre & 48 & 68 & 124 & 72 & 133 & 68 & 122 & 64 & 125 & 63 & 552 & \\
\hline \multicolumn{13}{|c|}{ Acesso à camisinha } \\
\hline Nunca & 7 & 11 & 10 & 8 & 10 & 7 & 15 & 10 & 21 & 14 & 63 & \\
\hline Às vezes & 4 & 7 & 11 & 8 & 10 & 7 & 13 & 9 & 7 & 5 & 45 & \\
\hline Sempre & 51 & 82 & 108 & 84 & 125 & 86 & 117 & 81 & 120 & 81 & 521 & 0,496 \\
\hline \multicolumn{13}{|c|}{ Deseja ter filhos? } \\
\hline Sim & 29 & 39 & 44 & 25 & 40 & 19 & 17 & 8 & 11 & 4 & 141 & $<0,001$ \\
\hline Não & 43 & 58 & 123 & 71 & 166 & 78 & 201 & 91 & 282 & 95 & 815 & \\
\hline Não sabe & 2 & 3 & 6 & 4 & 6 & 3 & 2 & 1 & 2 & 1 & 18 & \\
\hline Total & 80 & 100 & 188 & 100 & 229 & 100 & 238 & 100 & 325 & 100 & 1.060 & \\
\hline
\end{tabular}

* excluídas as mulheres com informação ignorada ou para quem a pergunta não se aplica. p\# = nível descritivo do teste de associação pelo qui-quadrado. 
Tabela 4

Número e porcentagem de mulheres, segundo variáveis de estudo e tempo de HIV.

\begin{tabular}{|c|c|c|c|c|c|c|c|c|c|c|}
\hline \multirow[t]{3}{*}{ Variável* } & \multicolumn{8}{|c|}{ Tempo que sabe que é HIV positiva } & \multirow{3}{*}{$\begin{array}{c}\text { Total } \\
\mathrm{n}\end{array}$} & \multirow[t]{3}{*}{$\mathrm{p}^{\#}$} \\
\hline & \multicolumn{2}{|c|}{$<1$} & \multicolumn{2}{|c|}{$1-4$} & \multicolumn{2}{|c|}{$5-9$} & \multicolumn{2}{|c|}{$10 e+$} & & \\
\hline & $n$ & $\%$ & $\mathrm{n}$ & $\%$ & $n$ & $\%$ & $\mathrm{n}$ & $\%$ & & \\
\hline \multicolumn{11}{|c|}{$\begin{array}{l}\text { Parceiro atual sabe } \\
\text { que é HIV+ }\end{array}$} \\
\hline Sim & 62 & 91 & 286 & 92 & 152 & 90 & 35 & 95 & 535 & 0,962 \\
\hline Não & 5 & 7 & 20 & 6 & 13 & 8 & 2 & 5 & 40 & \\
\hline Não sabe & 1 & 2 & 7 & 2 & 3 & 2 & - & - & 11 & \\
\hline \multicolumn{11}{|c|}{$\begin{array}{l}\text { Quantos parceiros } \\
\text { teve na vida? }\end{array}$} \\
\hline $1-2$ & 25 & 25 & 152 & 34 & 83 & 30 & 16 & 25 & 276 & 0,139 \\
\hline $3-4$ & 41 & 41 & 149 & 34 & 104 & 38 & 22 & 35 & 316 & \\
\hline $5-7$ & 20 & 20 & 83 & 19 & 53 & 19 & 11 & 18 & 167 & \\
\hline $8-10$ & 9 & 9 & 42 & 9 & 24 & 9 & 5 & 8 & 80 & \\
\hline $11-15$ & 2 & 2 & 14 & 3 & 7 & 3 & 4 & 6 & 27 & \\
\hline $16 e+$ & 3 & 3 & 6 & 1 & 4 & 1 & 5 & 8 & 18 & \\
\hline \multicolumn{11}{|c|}{ Parceiro fixo? } \\
\hline Sim & 68 & 56 & 311 & 60 & 166 & 50 & 37 & 43 & 582 & 0,004 \\
\hline Não & 54 & 44 & 212 & 41 & 169 & 50 & 49 & 57 & 484 & \\
\hline \multicolumn{11}{|c|}{ Parceiro atual é HIV + ? } \\
\hline Sim & 28 & 41 & 157 & 50 & 56 & 33 & 10 & 27 & 251 & 0,003 \\
\hline Não & 28 & 41 & 120 & 38 & 83 & 50 & 23 & 62 & 254 & \\
\hline Não sabe & 12 & 18 & 36 & 12 & 29 & 17 & 4 & 11 & 81 & \\
\hline \multicolumn{11}{|c|}{ Mora com parceiro? } \\
\hline $\operatorname{Sim}$ & 51 & 58 & 231 & 63 & 120 & 57 & 21 & 37 & 423 & 0,002 \\
\hline Não & 37 & 42 & 135 & 37 & 89 & 43 & 36 & 63 & 297 & \\
\hline \multicolumn{11}{|c|}{ Tem usado camisinha? } \\
\hline Nunca & 11 & 15 & 49 & 12 & 38 & 14 & 15 & 20 & 113 & 0,027 \\
\hline Às vezes & 13 & 18 & 67 & 17 & 59 & 21 & 23 & 30 & 162 & \\
\hline Sempre & 50 & 67 & 288 & 71 & 181 & 65 & 38 & 50 & 557 & \\
\hline \multicolumn{11}{|c|}{ Tem acesso à camisinha? } \\
\hline Nunca & 7 & 13 & 28 & 9 & 24 & 11 & 5 & 9 & 64 & \\
\hline Às vezes & 3 & 6 & 20 & 6 & 17 & 8 & 6 & 11 & 46 & \\
\hline Sempre & 42 & 81 & 268 & 85 & 172 & 81 & 44 & 80 & 526 & 0,750 \\
\hline \multicolumn{11}{|c|}{ Deseja ter filhos? } \\
\hline Sim & 18 & 16 & 78 & 16 & 31 & 10 & 16 & 19 & 143 & 0,178 \\
\hline Não & 91 & 82 & 392 & 82 & 270 & 89 & 66 & 80 & 819 & \\
\hline Não sabe & 2 & 2 & 11 & 2 & 4 & 1 & 1 & 1 & 18 & \\
\hline Total & 122 & 100 & 523 & 100 & 335 & 100 & 86 & 100 & 1.066 & \\
\hline
\end{tabular}

* excluídas as mulheres com informação ignorada ou não se aplica.

p\# = nível descritivo do teste de associação pelo qui-quadrado. 
O sentimento de que a camisinha atrapalha, mudando para pior a vida sexual depois do diagnóstico, ou sempre interfere de forma negativa no relacionamento, surgiu em $10 \%$ das respostas. Muitas $(6 \%)$ informaram que demoraram, mas se acostumaram (6\%). A camisinha nesse contexto de dificuldades não aparece como fator protetor, mas como mais um complicador para o relacionamento sexual, recusada por muitos homens que sabem que elas são portadoras, ou presente no espaço mais íntimo do casal para lembrá-los de algo que querem esquecer. Muitas indicaram que ela (16\%) ou o parceiro (2\%) perderam o desejo. $\mathrm{O}$ medo também é um dos motivos alegados para a vida sexual piorar para $15 \%$ delas: medo de engravidar, de infectar o parceiro, aumentar a carga viral, receio de o preservativo se romper, de se envolver afetivamente. A dificuldade para encontrar um parceiro (ressaltada por $1 \%$ delas), combina o medo de revelar o diagnóstico e da rejeição do parceiro, que contribui para a solidão, paralisia, depressão.

"Ficou diferente porque não vou ter relações sem camisinha, aí o cidadão acha ruim e acaba não tendo sexo!"

"A única pessoa que arrumei após o resultado não teve estrutura para ficar comigo. Ia para o banheiro, e se esfregava muito tempo, como para se limpar de alguma coisa."

Algumas acham que porque são portadoras do HIV não podem mais ter vida sexual (2\%), e um número significativo delas comentou que parou de fazer sexo depois do diagnóstico (16\%).

“...antigamente eu era uma pessoa feliz, hoje eu tenho medo, vergonha de mostrar o corpo e resolvi não ter mais nada há dois anos, hoje eu criei raiva... foi através disso (vida sexual).... que eu peguei AIDS!"

“...Por que eu estou desse jeito, nada mais tem para fazer, minha vida acabou por aqui, não quero mais parceiros..."

Entre aquelas que disseram que a vida sexual foi melhorando, a necessidade de aumentar o diálogo sobre sexualidade e a urgência de o casal se apoiar no momento difícil do diagnóstico tiveram um efeito positivo na qualidade da relação sexual (5\%). Outras narraram que foram amadurecendo, ficando mais experientes.

“...Porque agora conversamos bastante, $o$ sentimento supera o problema".

“Temos muita cumplicidade, e mais respeito."

“... A gente passa por uma fase de adaptação, muda muita coisa...”

Perguntadas sobre com quem se sentem mais à vontade para conversar sobre sua sexualidade no Centro onde são atendidas, as que têm contato com as diversas especialidades poderiam se sentir mais confortáveis. Das mulhe- res que têm acesso a cada especialidade profissional investigada, metade $(51 \%)$ refere que, na maioria das vezes, se sente à vontade para conversar sobre sua vida sexual com o ginecologista, $56 \%$ com o infectologista, $59 \%$ com o psicólogo, e uma proporção relevante delas indica o assistente social (33\%) e o enfermeiro (25\%). Quando analisamos a escala de "espaço" para falar de sua sexualidade - incluindo o acesso e o grau de conforto para falar com os vários especialistas -, os escores são muito baixos. A Figura 1 apresenta a distribuição das mulheres, segundo esse escore. Numa escala que variava de 0 a 15, o escore médio foi de 5,1 (desvio padrão $=2,8$ ) e $85 \%$ das mulheres têm escore até 8 , indicando que essas mulheres encontram pouco "espaço" para falar sobre sua vida sexual. O "espaço” para falar de sexualidade não se altera em função do tempo de diagnóstico ( $\mathrm{p}=$ 0,382 ) e não se observou diferença estatisticamente significativa entre as médias de escore de "espaço" e faixa etária (Tabela 2). Segundo as normas brasileiras de atendimento ao portador do HIV, a consulta pós-teste é um dos raros e importantes "espaços" para falar da sexualidade, obrigatório depois do diagnóstico. Mas uma em cada três mulheres entrevistadas recebeu o teste sem qualquer aconselhamento.

\section{Desejo de ter filhos, uso de preservativo} e contraceptivos

Do total de mulheres sexualmente ativas em algum momento depois do diagnóstico $(\mathrm{n}=833)$, $67 \%$ referiram que o parceiro usou camisinha masculina em todas as relações sexuais. Além disso, 93\% das entrevistadas já tinham ouvido falar do preservativo feminino, embora somente $11 \%$ já tivessem usado e gostado, e outras $16 \%$ usaram e não gostaram.

Encontramos associação estatisticamente significativa ( $\mathrm{p}<0,001)$ entre o uso do preservativo e a sorologia do parceiro atual. Das que tinham parceiro também portador do HIV, 59\% sempre usavam camisinha. Esta porcentagem aumentava para $64 \%$, quando a mulher não conhecia a sorologia do parceiro atual e para $79 \%$, quando sabia que o parceiro é soronegativo.

Das 719 mulheres que responderam por que usavam ou não o preservativo, um terço delas usava a camisinha pensando em reinfecção, e a maioria indicou como razão para usar o preservativo a proteção do parceiro:

"Porque eu acho que é um crime você saber que tem a doença e ir para cama com alguém que não tem."

"Mesmo sendo os dois HIV positivos, o médico orientou para não aumentar os vírus." 
“Temos que pensar nos nossos filhos!"

"Porque sou consciente, mas tem homem que não quer usar, aí tira! Fazer o quê?"

A maioria das mulheres que não usava o preservativo consistentemente afirmou que "o parceiro não gostava de usar" (61\%), ou que "ela não gostava também" (17\%). Muitas entrevistadas alegaram esquecimento (12\%).

"Quando vi, já foi...”

"Meu marido não quer saber de usar. Não consigo mais sentir prazer por isso."

"Ele perde a ereção se usar."

"Eu creio em Deus. Nós não vamos morrer por causa disso".

"Meu marido não aceita, é briga na certa!"

Somento quatro mulheres alegaram dificuldade de acesso ao preservativo e 6 comentaram que não sabiam que era necessário usar, além de 3 mulheres que não usavam porque não conseguiam comunicar ao parceiro que são portadoras e tinham dificuldades de convencê-lo. Poucas mulheres $(n=28)$ indicaram a duplaproteção (contra o HIV e a gravidez ao mesmo tempo) como motivo para usar a camisinha.

Considerando todas as participantes (1.068 entrevistadas), 73\% têm filhos, em média 1,8 filhos e 28 estavam grávidas no momento da entrevista. Uma fração importante delas $(\mathrm{n}=143)$ desejava ter filhos, apesar do diagnóstico, e 18 mulheres tinham dúvidas a respeito. Entre as mais jovens, a proporção de mulheres que desejava ter filhos era maior (Tabela 2 e 3), e não se observou associação do tempo sabendo do diagnóstico ao desejo ou não de ter filhos (Tabela 4). A maioria absoluta das mulheres que desejava ter filhos não tem nenhum, ou tem apenas um. Elas explicam seu desejo com base na sua "realização como mulher", ou de "constituir uma família”. As que estão em dúvida têm medo, algumas falam em adotar, outras dizem que o parceiro quer ser pai.

Caso se observe que métodos para evitar filhos foram usados por todas elas depois do diagnóstico, apenas 6\% usaram dupla-proteção (preservativo e mais um método), e 51\% usaram apenas a camisinha. Muitas usaram apenas métodos que não protegem da reinfecção: $7 \%$ indicaram coito interrompido; $14 \%$ usaram métodos hormonais; $5 \%$, laqueadura; $0,5 \%$, vasectomia; e $4 \%$ usaram outros métodos (diafragma, além da tabelinha e o dispositivo intrauterino - DIU - que são contra-indicados para portadoras do HIV). Uma fração relevante de mulheres estava laqueada antes do diagnóstico (13\%). Entre as mulheres que tinham vida sexual e não estavam grávidas no momento da entrevista, $23 \%$ não estavam usando nenhum método de proteção, $43 \%$ usavam apenas ca-
Figura 1

Número de mulheres, segundo o escore "espaço" para falar sobre sua vida sexual.

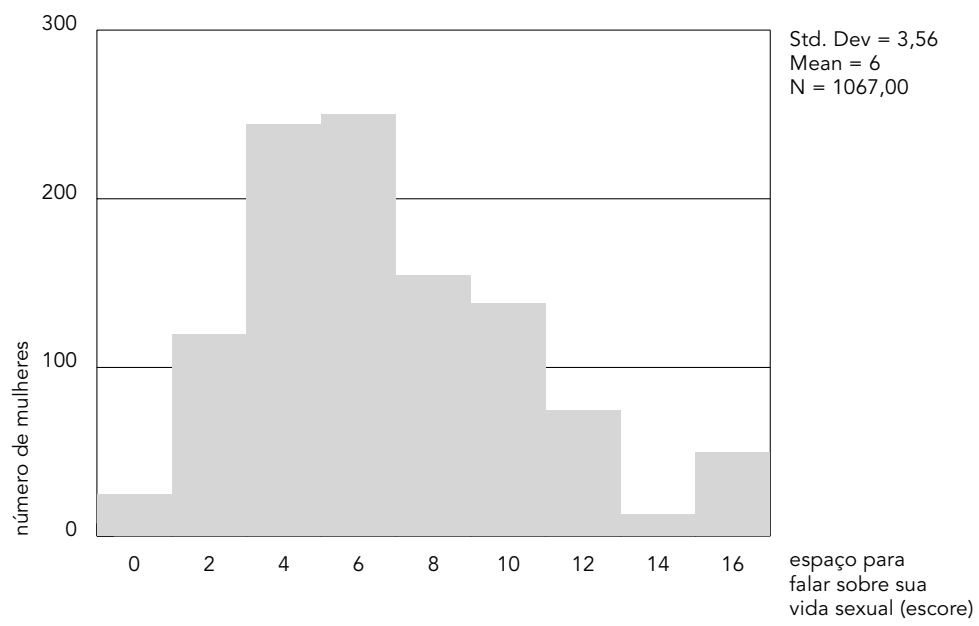

misinha, 2\% usavam métodos hormonais, $25 \%$ indicaram que estavam esterilizadas ou que o marido fez vasectomia.

É alta a proporção de entrevistadas que não foi informada da existência de práticas contraceptivas mais indicadas para mulher vivendo com HIV/AIDS (53\%). É também alta a proporção que não foi informada de que poderia transmitir o vírus para o bebê (25\%). Além disso, $27 \%$ delas não sabiam que o vírus se transmite durante o parto ou durante a amamentação (24\%), que existe medicação específica para a mãe durante a gestação $(24 \%)$ e para o bebê (30\%). Estão melhor informadas, hoje, sobre a necessidade de se protegerem e aos seus parceiros sexuais da (re)infecção (85\%).

Perguntou-se a todas as mulheres: "Se você disser ao médico que a acompanha - Eu quero ter um filho - qual você acha que será a reação dele?" A resposta de quase todas as mulheres a essa pergunta aberta é relevante: a maioria achava que seu médico iria se opor a priori, e um terço delas acha que o médico iria dizer claramente que não concorda ou "que é loucura":

"Ela ia me dar uma bronca, nem sei bem por quê. Mas já tenho uma menina”.

"Vai dizer que sou louca, só louca para ter filho sabendo que é portadora do HIV... aquela que engravida sofre muito pela culpa da doença na criança".

Cerca de $6 \%$ acham que o médico acrescentaria a informação de que o bebê tem chance de ser também portador; $4 \%$ que argumenta- 
riam prejuízo à saúde da paciente; e 5\% diriam apenas que para uma portadora é contra-indicado. Ainda, $8 \%$ das mulheres acharam que o seu médico iria propor que pensassem melhor antes de tomar uma decisão que considera "não aconselhável para portadoras”, 5\% lembrariam as condições de vida da mulher (solteira, pobre).

"Sério? Mas por quê? Você tá doida? Tem certeza? Ele não ficaria muito feliz, mas me orientaria muito bem."

"Vai falar que eu sei que não posso ter filhos por causa da doença”.

"Ele vai me dizer para não engravidar para não correr o risco de minha filha nascer com o vírus".

Apenas $27 \%$ das mulheres achavam que o seu médico lhe forneceria todas as informações relevantes para que elas pudessem tomar uma decisão e as apoiaria em qualquer decisão. As demais lembraram que não querem ter filhos ou que “já não podem mais” (estão na menopausa ou laqueadas).

\section{Discussão}

A grande maioria das entrevistadas neste estudo (ECI), que reuniu o maior número de mulheres portadoras no país até hoje, relatou poucos parceiros na vida, confirmando as análises que indicam que a epidemia feminina no Brasil cresce entre mulheres de relacionamentos estáveis. A média de início da vida sexual das mais jovens (mulheres com menos de 24 anos) é comparável à média nacional (CEBRAP, 1999). No entanto, em todas as outras coortes das mulheres entrevistadas (ECI), se compararmos com os resultados da pesquisa sobre comportamento sexual da população brasileira (CEBRAP, 1999) (BR), a média de início da vida sexual é cerca de um ano e meio mais baixa entre as mulheres do ECI. Por outro lado, a porcentagem de mulheres sexualmente ativas é menor entre as entrevistadas (54\% ECI X 70\% BR), assim como a proporção que mantém relações sexuais com parceiros casuais é maior na amostra nacional (5\% BR X 3\% ECI). A porcentagem de uso consistente de preservativos relatada pelas mulheres entrevistadas, por outro lado, é três vezes maior que a média nacional $(21 \% \mathrm{BR} X$ $67 \%$ ECI), indicando que os programas especializados podem fazer diferença, apesar do contexto. Não se pode esquecer que as relações de gênero, as condições de vida, o contexto sóciocultural que facilitaram a transmissão sexual do HIV não desaparecem depois do diagnóstico.

Em relação ao número de filhos, a média no Estado de São Paulo é de 2,2 filhos por mulher, e o número de filhos naturais das mulheres entrevistadas está próximo ao número desejado de filhos entre as mulheres do Estado, que é 1,7 filhos (média) (BEMFAM, 1997). Os resultados deste estudo (ECI) são também consistentes com outros estudos com mulheres vivendo com HIV/AIDS realizados no Estado de São Paulo em 1997-98 quanto à proporção de casais discordantes, ao uso de preservativo, à diminuição na atividade sexual, ao número de filhos e ao uso de contraceptivos (Magalhães, 1998; Santos et al., 1998).

A grande maioria das mulheres portadoras segue mantendo ativa vida sexual e afetiva; contudo, enfrenta dificuldades de comunicação do diagnóstico, da negociação permanente cotidiana da camisinha, do medo da rejeição, de decisões difíceis quanto aos desejos de constituir família. Os resultados, também observados em um estudo que experimentava formas de apoiar as portadoras nos seus cuidados com a saúde e decisões sobre a vida sexual (Tunala et al., 2000), mostram pouco acolhimento para o desejo de ser mãe, dimensão tão central e eixo da construção da identidade feminina no Brasil (Barbosa, 1999; Parker \& Galvão, 1996). A forma como percebem a atitude dos médicos sobre um possível desejo de ser mãe (basicamente temendo uma "reprimenda") pode explicar o índice insuficiente de informação que as mulheres declaram sobre a prevenção/transmissão materno-infantil (TMI). Chama a atenção o fato de que a qualidade do acolhimento a essa dimensão da vida não ter melhorado com o tempo, ou com o tempo de conhecimento do diagnóstico, mesmo nestes centros de referência estadual ou nacional. A mesma avaliação de falta de "espaço" para conversar sobre sexualidade e reprodução com os vários profissionais, assim como a força do desejo (à sombra de qualquer orientação muitas vezes) de ter pelo menos um ou dois filhos entre as mulheres portadoras, como entre as paulistas, já tinha sido indicada por Santos (1998). O estudo de Magalhães (1998), realizado em um centro especializado em saúde reprodutiva e não em HIV, e que pretendeu analisar o efeito do aconselhamento sobre uso de métodos contraceptivos entre mulheres portadoras, encontrou o dobro da proporção de mulheres utilizando a recomendada "dupla-proteção" depois de passarem por aconselhamento que abordava sua vida reprodutiva pós-HIV.

Uma parte significativa das mulheres foi diagnosticada durante a gravidez ou quando adoeceu, comprometendo a possibilidade de início precoce do tratamento e conseqüente chance de usufruir da medicação disponível 
gratuitamente na rede pública. Talvez os profissionais encontrem dificuldades de superar a visão do paciente fragilizado pela doença ou se preocupem com o impacto futuro na sobrevivência das crianças, particularmente porque o número de mulheres empobrecidas é grande entre as portadoras. Porém, a lenta adequação dos serviços que atendem as pacientes soropositivas demonstra que a feminização da epidemia precisa fazer frente às necessidades de saúde e qualidade de vida como mulher de forma integral, e, sobretudo, considerar seus direitos como mulher brasileira. As mulheres nos indicam que não encontram espaço suficiente em que se sintam mais à vontade para conversar sobre sua vida sexual, conforto que deveria ser maior se pensarmos no impacto que o uso inconsistente de camisinha pode ter para a sua saúde e a de seus parceiros. Ao mesmo tempo, o número de mulheres que nunca foi atendida em aconselhamento chama a atenção, especialmente porque vivem em cidades com um grande número de casos e onde, supostamente, concentram-se bons recursos especializados. Parece importante divulgar evidências (Lylerly \& Anderson, 2001) e decisões como a do Conselho Regional de Medicina do Estado de São Paulo, afirmando que "serviços e instituições de saúde, públicos e privados, devem proporcionar condições para o exercício profissional, disponibilizando exames, medicamentos e outros procedimentos necessários ao diagnóstico e tratamento da infecção pelo HIV em gestantes, bem como assistência ao pré-natal, parto, puerpério e atendimento ao recém-nascido" (CREMESP, 2000:48).

Os mesmos determinantes sócio-culturais que constroem as várias formas de significar a sexualidade e a identidade feminina, aumentando sua vulnerabilidade ao HIV e depois à AIDS (Mann et al., 1992), podem estar dificultando a melhor organização dos serviços de saúde, como já se descreveu em outros estudos que mostraram que a prática clínica pode reforçar as normas e a hierarquia de gênero para a sexualidade (Giffin \& Lowndes, 1999). A literatura sobre a prevenção do HIV e programas de educação sexual indicam que a informação completa, o debate de valores e o apoio para que cada um decida como encaminhar a vida nunca aumentam comportamentos "pouco saudáveis”; ao contrário, estimulam decisões e atos bem pensados e bem informados, estimulam sexo protegido, mesmo entre os mais jovens (UNAIDS, 1997).

O modelo assistencial deve facilitar um fluxo contínuo, evitando a lacuna entre o momento do teste e a comunicação do diagnóstico e o seguimento cotidiano nos serviços de atendimento especializado; deve acolher a mulher para além do manejo da sua carga viral. $\mathrm{O}$ aconselhamento deve deixar de ser pontual (pós-teste, pós-gravidez) para ser parte de um processo contínuo e adequado a todas as fases da infecção ou da vida da paciente. O contínuo entre prevenção primária e secundária deve se aprofundar; propostas de programas de prevenção, sempre dedicados aos "soronegativos", devem ir além do habitual "treinamento" para o uso da camisinha, desconsiderando os obstáculos culturais e o contexto social em que vivem as mulheres, semelhantes antes e depois do diagnóstico. O investimento em aconselhamento e grupos de apoio nesta área deve estimular a formação de equipes especializadas, interdisciplinares que possam servir como referência para o atendimento direto ao paciente, ou para estar apoiando o trabalho cotidiano da prática de médicos, enfermeiros e atendentes, assistentes sociais e demais profissionais envolvidos diretamente com o portador.

Viver a soropositividade de forma integral e com qualidade de vida tem sido uma conquista conjunta da mobilização dos portadores e muitos profissionais de saúde dedicados aos direitos humanos e à saúde. A reflexão sobre os direitos sexuais e reprodutivos do portador do HIV, ou mesmo a disposição e capacitação de profissionais de saúde para promover a saúde sexual e reprodutiva de portadores do HIV/ AIDS, que se pressupõe indissociável da discussão de direitos, precisa ser abertamente incentivada nos serviços especializados. Enquanto se mantiverem as controvérsias nos cantos de clínicas e hospitais, e a visibilidade da mulher portadora permanecer amarrada à dicotomia patriarcal tradicional que divide as mulheres entre "mulher da rua e do sexo" (que tem AIDS e não pode pensar em ter filhos) e "mulher da casa e dos filhos" (que não pode ter HIV e para quem não se oferece teste), a prevenção e a qualidade de vida das mulheres portadoras e suas famílias estarão prejudicadas. 


\section{Agradecimentos}

V. Paiva e M. do R. Latorre agradecem ao Conselho Nacional de Desenvolvimento Científico e Tecnológico a bolsa de pesquisadoras. À contribuição e parceria de Sofia Gruskin, do Instituto François-Xavier Bagnoud Center for Health and Human Rights, Havard University e de Dr. Richard Marlink, da Harvard School of Public Health, Coordenador do Enhacing Care Iniative, uma iniciativa multicêntrica com financiamento da Merck Company Foundation.

\section{Referências}

BARBOSA, R., 1999. Negociação sexual ou sexo negociado? Poder, gênero e sexualidade em tempos de Aids. In: Sexualidades pelo Avesso (R. Barbosa \& R. Parker, org.), pp. 73-89, São Paulo: Editora 34.

BEMFAM (Sociedade Civil Bem Estar Familiar no Brasil), 1997. Pesquisa Nacional de Demografia e Saúde. Relatório. Rio de Janeiro: BEMFAM.

CEBRAP (Centro Brasileiro de Análise e Planejamento)/MS (Ministério da Saúde), 1999. Comportamento Sexual da População Brasileira e Percepções sobre HIV e AIDS. Versão Preliminar do Relatório de Pesquisa/Julho. Abril de $2001<w w w$. aids.gov.br>.

CLARK, K.; FINALYON, R.; LAMGHORESE, R.; BUSCH, M. \& STEKETEE, R., 2000. Prevalence and risk behavior among HIV positive blood donors. In: 13th World Aids Conference, Proceedings, CD-ROM, Durban: Marathon Mutlimidia.

CREMESP (Conselho Regional de Medicina do Estado de São Paulo), 2000. Resolução № 95, aprovada na 2528a sessão plenária realizada em 14 de novembro de 2000. São Paulo: Diário Oficial do Estado de São Paulo, Seção I, no 223, p. 48, 22 nov.

GIFFIN, K. \& LOWNDES, C. M., 1999. Gender, sexuality, and the prevention of sexually transmissible diseases: A Brazilian study of clinical practice. Social Science and Medicine, 48:283-292.

FELDMAN, R. \& MAPOSHERE, C., 2000. Voices and choices - a participatory research and advocacy of reproductive. In: 13th World Aids Conference, Proceedings, CD-ROM, Durban: Marathon Mutlimidia.

LYLERLY, A. D. \& ANDERSON, J., 2001. Human immunodeficiency virus and assisted reproduction: Reconsidering evidence, reframing ethics. Fertility and Sterility, 75:843-858.

MAGALHÃES, J.,1998. Mulheres Infectadas pelo HIV: O Impacto na Anticoncepção, no Comportamento Sexual e na História Obstétrica. Dissertação de Mestrado, Campinas: Departamento de Tocoginecologia, Faculdade de Ciências Médicas, Universidade Estadual de Campinas.

MANN, J.; TARANTOLA, D. M. \& NETTER, T. W. (ed.), 1992. Aids in the World. Cambridge: Harvard University Press.

MS (Ministério da Saúde), 2001. Boletim Epidemiológico - AIDS, XIV(2), Semana Epidemiológica 14 a 26, abril/junho.
PARKER, R. \& GAGNON, J., 1995. Conceiving sexuality. In: Conceiveing Sexuality: Approaches to Sex Research in a Post-modern World (R. Parker \& J. Gagnon, ed.), pp. 3-19, New York/London: Routledge.

PARKER, R. \& GALVÃO, J. (org.), 1996. Quebrando o Silêncio - Mulheres e AIDS no Brasil. Rio de Janeiro: Relume Dumará/Instituto de Medicina Social, Universidade do Estado do Rio de Janeiro.

RODRIGUES, L. C.; TESS, B. H. \& LAGO, T. M. G., 1998. Reproductive intentions and practices of HIV Infected women in São Paulo, Brazil. In: 12th World AIDS Conference, Proceedings, CD-ROM, Geneva: Marathon Multimidia.

SANTOS, N. J.; VENTURA-FELIPE, E. \& PAIVA, V., 1998. HIV positive women, reproduction and sexuality in Sao Paulo, Brazil. Reproductive Health Matters, 6:31-41.

SCHILTZ, M. A. \& SANDFORTH, T. G., 2000. HIV-positive people, risk and sexual behavior. Social Science and Medicine, 50:1571-1588.

THIOYE, M. C.; IBRA, I. N. \& ANOTOINE, M., 2000. Problems in notify a seropositive status to the regular partners of HIV + prostitutes registred in STD Center of DAKAR/Senegal. In: 13 th World Aids Conference, Proceedings, CD-ROM, Durban: Marathon Mutlimidia.

TUNALA, L.; PAIVA, V.; VENTURA-FELIPE, E.; SANTOS, T.; SANTOS, N. \& HEARST, N., 2000. Fatores psicossociais que dificultam a adesão das mulheres portadoras do HIV aos cuidados de saúde. In: Tá Dificil de Engulir (P. Teixeira, V. Paiva \& E. Shimma, org.), pp. 83-115, São Paulo: Núcleo de Estudos para Prevenção da AIDS, Centro de Referência e Treinamento em DST-AIDS.

UNAIDS (Joint United Nations Programme on HIV/ AIDS), 1997. Impacto de la Educación en Materia de Salud Sexual y VIH sobre el Comportamiento Sexual de los Jóvenes. Colección Práticas Optimas/Materiales Básicas. Geneva: UNAIDS.

WILLIAMS, H.; WATKINS, C. E. \& RISBY, J. A., 1996. Reproductive decision making and determinants of contraceptive use in HIV - Infected women. Clinical Obstetrics and Gynecology, 39:333-343.

Recebido em 25 de outubro de 2001

Versão final reapresentada em 27 de fevereiro de 2002 Aprovado em 15 de abril de 2002 